\title{
Effects of the Peripheral Heteroaryl Substituents on the Photochromism of New Pyridine-Containing Diarylethenes
}

\author{
Guanming Liao, Dandan Xue, Chunhong Zheng, * Renjie Wang and Shouzhi Pu* \\ Jiangxi Key Laboratory of Organic Chemistry, Jiangxi Science and Technology Normal University, \\ 330013 Nanchang, P. R. China
}

\begin{abstract}
Three new unsymmetrical pyridine-containing diarylethenes with a variable peripheral heteroaryl unit were synthesized and their structures were determined by single-crystal X-ray diffraction analysis. The substituent effects of variable heteroaryl groups on the photochromic and fluorescence properties were systematically discussed. Thienyl and thiazyl could effectively enhance the cyclization quantum yields and photoconversion ratios in the photostationary state, as compared to the phenyl group. However, they had no obvious effect on the fluorescence behaviors. Moreover, X-ray structural analysis revealed that the $\mathrm{N} \cdots \mathrm{S}$ heteroatom-contact interactions resulted in a higher cyclization quantum yield, which may be ascribed to the effective stabilizing ability on the photoreactive formations in diarylethenes with a thienyl/thiazyl unit.
\end{abstract}

Keywords: diarylethene, photochromism, pyridine moiety, $\mathrm{N} \cdots \mathrm{S}$ interaction, substituent effect

\section{Introduction}

Among various photochromic molecules, diarylethenes are particularly attractive due to the excellent thermal stability of both isomers and their notable fatigue resistant property. ${ }^{1-3}$ The photochromic properties mainly depend on several factors, such as conformations of the open-ring isomers, nature of heteroaryl moieties, and electronic properties of substituents. ${ }^{4-7}$

Generally, changes in heteroaryl moieties result in significant modification of the photochromic behaviors of photochromic diarylethenes. To date, the design and synthesis of diarylethene derivatives have mainly focused on the variation of two heteroaryl moieties, which stimulated character diversity of this class of molecules. ${ }^{1}$ For example, diarylethenes having two thiophene moieties exhibit outstanding thermal stability and outstanding fatigue resistance, ${ }^{1,8}$ whereas symmetrical diarylethenes having two pyrrole groups are thermally unstable and return to the open-ring isomers even in the dark. ${ }^{9}$ In the case of six-membered heteroaryl rings, diarylethenes having two phenyl/naphthyl groups are thermally reversible with poor photochromism, ${ }^{10,11}$ but some unsymmetrical diarylethenes having a six-membered heteroaryl ring are thermally irreversible with good photochromism. ${ }^{12,13}$ Among the

*e-mail: articlechem@163.com,pushouzhi@tsinghua.org.cn reported diarylethenes, pyridine-containing diarylethenes have attracted much attention because the photochromic reactivity could be effectively modulated by external stimuli. ${ }^{14-16}$ In most cases, pyridine was introduced to the diarylethenes as a peripheral substituent. ${ }^{17-19}$ In previous works, we reported some diarylethenes with a pyridine moiety directly linked at the central cyclopentene moiety and elucidated their specific photoactive characteristics. ${ }^{20}$ The results obtained have contributed to a broad understanding of the photochromism of pyridine-containing diarylethene derivatives.

Apart from the fact that heteroaryl rings have significant effects on the photochromic characteristics of diarylethenes, various functional substituents and their substituted positions have also remarkable effects on their properties, which can be used for the fine-tuning of the optoelectronic properties of photochromic diarylethenes. So far, many reports concerning the substituent effects on the properties of diarylethene derivatives have been reported. ${ }^{6,21-23}$ From these publications, it can be concluded that the reported substituents are usually simple functional groups. In this study, using variable heteroaryl rings (benzene, thiophene, and thiazole) as peripheral groups, we have synthesized three new pyridine-containing diarylethenes to elucidate the substituent effects of heteroaryl groups on the photochromic behaviors of these diarylethene derivatives (Figure 1). As far as we are aware, this is the first report where various 

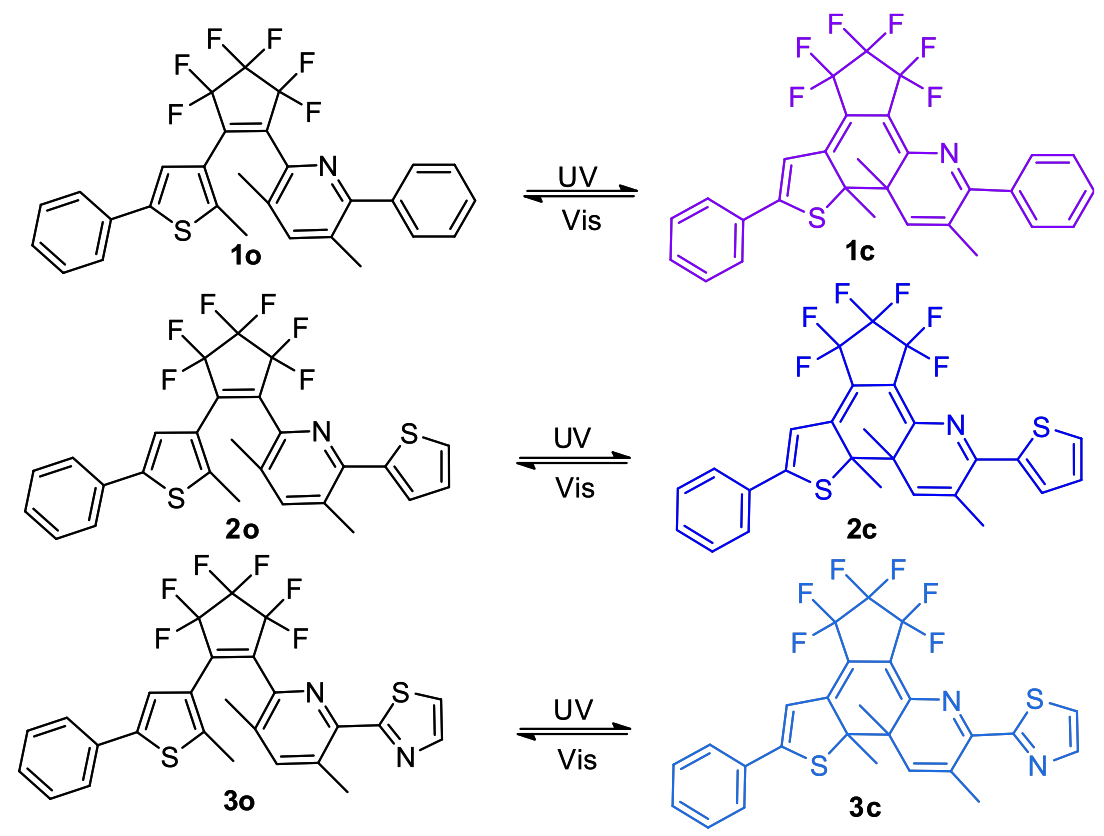

Figure 1. Photochromism of 1-3.

heteroaryl rings were used as peripheral substituents to study the substituent effects on the photochromism of diarylethenes.

\section{Experimental}

\section{General methods}

Chemical reagents were purchased from J\&K Scientific Ltd. and used without further purification. All solvents used were spectroscopic grade and were purified by distillation before use. All solution-phase reactions were performed under an atmosphere of dry argon or nitrogen. Reactions were monitored by analytical thin-layer chromatography on plates coated with $0.25 \mathrm{~mm}$ silica gel $60 \mathrm{~F} 254$ and $\mathrm{Al}_{2} \mathrm{O}_{3}$. High-performance liquid chromatograpy (HPLC) analysis was performed by an Agilent 1200 instrument fitted with a ZORBAX SIL column (5 $\mu$ m particle size, $4.6 \mathrm{~mm}, 25 \mathrm{~cm}$ ); the wavelength in the detector of HPLC analysis was $297 \mathrm{~nm}$. Melting points were measured with a WRS-1B melting point apparatus. Infrared (IR) spectra were recorded on a Bruker Vertex-70 spectrometer. Nuclear magnetic resonance (NMR) spectra were obtained with a Bruker AV-400 spectrometer with tetramethylsilane (TMS) as internal reference and $\mathrm{CDCl}_{3}$ as solvent. Elemental analysis was carried out with a PE CHN 2400 analyzer. Mass spectra (MS) were measured with an Agilent 1100 ion trap MSD spectrometer. Absorption spectra were obtained with an Agilent 8453 UV-Vis spectrometer. Photoirradiation was carried out with an SHG-200 UV lamp, a CX-21 ultraviolet fluorescence analysis cabinet, and a BMH-250 visible lamp. The light intensity was $25 \mu \mathrm{W} \mathrm{cm} \mathrm{cm}^{-2}$ and $13.5 \mathrm{~mW} \mathrm{~cm}^{-2}$ for UV and Vis lamps, respectively. The required wavelength was isolated by the use of the appropriate light filters. Fluorescence properties were measured with a Hitachi F-4600 spectrophotometer. $\mathrm{X}$-Ray experiments of single-crystal were performed on a Bruker SMART APEX2 CCD area-detector equipped with graphite monochromatized Mo $\mathrm{K} \alpha$ radiation at room temperature $(294 \pm 2 \mathrm{~K})$. Quantum yield was measured using 1,2-bis(2-methyl-5-phenyl-3-thienyl) perfluorocyclopentene as references for the cyclization and the cycloreversion reactions, respectively. The absorbances of the sample and reference at the irradiation wavelength $(297 \mathrm{~nm})$ were adjusted to be the same for the cyclization quantum yield measurement. The reaction rates of the sample and reference were measured in the same conditions and compared. For the cyclization quantum yield measurement, absorbance (A) at the absorption maximum of the closed-ring isomer was plotted against time. For the cycloreversion quantum yield measurement, $-\log \mathrm{A}$ at the absorption of the irradiated wavelength was plotted against time. The measurement was carried out three times, and the value was determined by averaging.

\section{Synthesis}

The synthesis route for diarylethenes $\mathbf{1 0 - 3 0}$ is shown in Figure 2. 2,6-Dibromo-3,5-dimethylpyridine (4) was lithiated and coupled with (2-methyl-5-phenyl-3thienyl)perfluorocyclopentene (5) to give the precursor diarylethene (6). The target diarylethenes 10-3o 

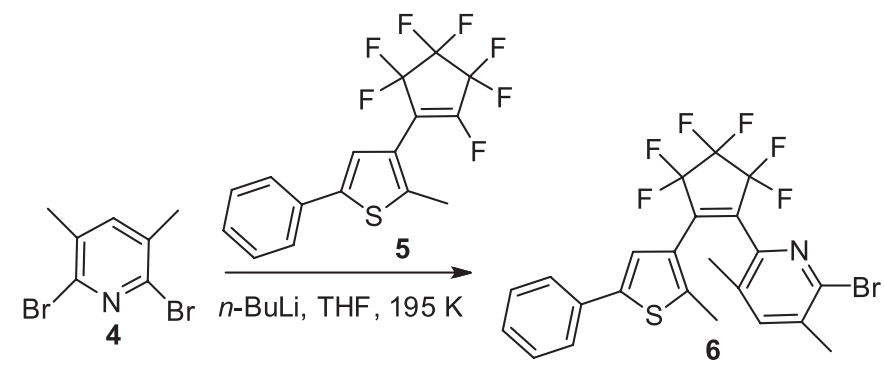

Figure 2. Synthetic route to $\mathbf{1 0 - 3 0}$

were afforded by reacting 6 with phenylboronic acid, 2-tributylstannylthiophene, and 2-tributylstannylthiazole, respectively. The structures of 10-3o were confirmed by NMR, IR, MS, elemental analysis, and single-crystal $\mathrm{X}$-ray diffraction analysis.

\section{2,6-Dibromo-3,5-dimethylpyridine (4)}

To a stirred oleum solution $(40 \mathrm{~mL})$ of 3,5-dimethylpyridine $(5.35 \mathrm{~g}, 50 \mathrm{mmol})$ at $273 \mathrm{~K}$ was added dropwise $\mathrm{Br}_{2}(5.64 \mathrm{~mL}, 110 \mathrm{mmol})$. Stirring continued for $0.5 \mathrm{~h}$ at $273 \mathrm{~K}$. Then the reaction mixture was heated to $353 \mathrm{~K}$ and refluxed for $36 \mathrm{~h}$. The solution was cooled to room temperature, poured into water slowly, and neutralized by aqueous $\mathrm{NaOH}$. After being extracted with dichloromethane, the organic layer was washed with water, and dried over anhydrous $\mathrm{Na}_{2} \mathrm{SO}_{4}$. The crude product was purified by column chromatography on silica gel using dichloromethane as eluent to afford $\mathbf{4}$ $(10.71 \mathrm{~g}, 80 \%)$ as a white solid. m.p. $102-103{ }^{\circ} \mathrm{C} ;{ }^{1} \mathrm{H}$ NMR $\left(400 \mathrm{MHz}, \mathrm{CDCl}_{3}\right) \delta 7.28(\mathrm{~s}, 1 \mathrm{H}$, pyridine-H), $2.24(\mathrm{~s}$, $\left.6 \mathrm{H},-\mathrm{CH}_{3}\right)$.

\section{(2-Methyl-5-phenyl-3-thienyl)perfluorocyclopentene (5)}

To a stirred anhydrous tetrahydrofuran (THF) solution of 3-bromo-5-phenyl-2-methylthiophene (1.73 g, $7.01 \mathrm{mmol}$ ) was added dropwise a $2.4 \mathrm{~mol} \mathrm{~L}^{-1} n$-BuLi in hexane solution $(3.2 \mathrm{~mL}, 7.70 \mathrm{mmol})$ at $195 \mathrm{~K}$ under argon atmosphere. Stirring continued for $0.5 \mathrm{~h}$ at $195 \mathrm{~K}$; octafluorocyclopentene $\left(\mathrm{C}_{5} \mathrm{~F}_{8}\right)(1.05 \mathrm{~mL}, 7.75 \mathrm{mmol})$ was added and the reaction mixture was stirred for $1 \mathrm{~h}$ at this temperature. The reaction was quenched by addition of water. After being extracted with dichloromethane, the organic layer was washed with water, and dried over anhydrous $\mathrm{Na}_{2} \mathrm{SO}_{4}$. The crude product was purified by column chromatography on silica gel using petroleum ether as eluent to afford $\mathbf{5}(1.30 \mathrm{~g}, 54 \%)$ as a yellow solid. m.p. 38-39 ${ }^{\circ} \mathrm{C} ;{ }^{1} \mathrm{H}$ NMR (400 MHz, $\left.\mathrm{CDCl}_{3}\right) \delta 2.42$ (s, $\left.3 \mathrm{H},-\mathrm{CH}_{3}\right), 7.18(\mathrm{~d}, 1 \mathrm{H}$, thienyl-H), $7.25(\mathrm{t}, 1 \mathrm{H}, J 8.0 \mathrm{~Hz}$, phenyl-H), 7.33 (t, 2H, J $8.0 \mathrm{~Hz}$, phenyl-H), $7.48(\mathrm{~d}, 2 \mathrm{H}$, phenyl-H).

1-(2-Methyl-5-phenyl-3-thienyl)-2-(6-bromo-3,5-dimethyl-2pyridyl)perfluorocyclopentene (6)

To a stirred anhydrous THF solution of $4(3.22 \mathrm{~g}$, $12.15 \mathrm{mmol}$ ) was added dropwise a $2.4 \mathrm{~mol} \mathrm{~L}^{-1} n$-BuLi in hexane solution $(5.57 \mathrm{~mL}, 13.37 \mathrm{mmol})$ at $195 \mathrm{~K}$ under argon atmosphere. Stirring continued for $0.5 \mathrm{~h}$ at $195 \mathrm{~K}$; a solution of (2-methyl-5-phenyl-3-thienyl)perfluorocyclopentene $(4.90 \mathrm{~g}, 13.37 \mathrm{mmol})$ in THF was added and the reaction mixture was stirred for $1 \mathrm{~h}$ at this temperature. The reaction was quenched by addition of water. After being extracted with dichloromethane, the organic layer was washed with water, and dried over anhydrous $\mathrm{Na}_{2} \mathrm{SO}_{4}$. The crude product was purified by column chromatography on $\mathrm{Al}_{2} \mathrm{O}_{3}$ using petroleum ether as eluent to afford $6(1.96 \mathrm{~g}, 28 \%)$ as a white solid. m.p. 86-87 ${ }^{\circ} \mathrm{C} ;{ }^{1} \mathrm{H}$ NMR (400 MHz, $\left.\mathrm{CDCl}_{3}\right) \delta 1.83$ (s, $\left.3 \mathrm{H},-\mathrm{CH}_{3}\right), 2.00\left(\mathrm{~s}, 3 \mathrm{H},-\mathrm{CH}_{3}\right), 2.29\left(\mathrm{~s}, 3 \mathrm{H},-\mathrm{CH}_{3}\right), 7.10$ (s, 1H, thiophene-H), $7.25(\mathrm{t}, 2 \mathrm{H}, J 8.0 \mathrm{~Hz}$, benzene-H), 
$7.33(\mathrm{t}, 2 \mathrm{H}, J 8.0 \mathrm{~Hz}$, benzene-H, pyridine-H), $7.48(\mathrm{~d}, 2 \mathrm{H}$, $J 4.0 \mathrm{~Hz}$, benzene-H).

1-(2-Methyl-5-phenyl-3-thienyl)-2-(3,5-dimethyl-6-phenyl-2yl-pyridin-2-yl)perfluorocyclopentene (10)

A stirred THF solution of $6(0.2 \mathrm{~g}, 0.38 \mathrm{mmol})$, phenylboronic acid $(0.068 \mathrm{~g}, 0.56 \mathrm{mmol}), \mathrm{Pd}\left(\mathrm{PPh}_{3}\right)_{4}$, and $\mathrm{Na}_{2} \mathrm{CO}_{3}$ was refluxed for $24 \mathrm{~h}$ under argon atmosphere. The reaction was slowly cooled to room temperature, and concentrated in vacuo. After being extracted with ethyl acetate, the organic layer was dried over anhydrous $\mathrm{Na}_{2} \mathrm{SO}_{4}$. The crude product was purified by column chromatography on $\mathrm{Al}_{2} \mathrm{O}_{3}$ using petroleum ether as eluent and afforded $\mathbf{1 0}$ $(0.12 \mathrm{~g}, 40 \%)$ as a colorless crystal. m.p. $122-123{ }^{\circ} \mathrm{C}$; ${ }^{1} \mathrm{H} \mathrm{NMR}\left(400 \mathrm{MHz}, \mathrm{CDCl}_{3}\right) \delta 1.92\left(\mathrm{~s}, 3 \mathrm{H},-\mathrm{CH}_{3}\right), 1.97$ (s, $\left.3 \mathrm{H},-\mathrm{CH}_{3}\right), 2.29\left(\mathrm{~s}, 3 \mathrm{H},-\mathrm{CH}_{3}\right), 7.16(\mathrm{~s}, 1 \mathrm{H}$, thiophene-H), $7.23(\mathrm{~d}, 1 \mathrm{H}$, pyridine-H), $7.29(\mathrm{t}, 3 \mathrm{H}, J 4.0 \mathrm{~Hz}$, benzene-H), $7.32(\mathrm{~d}, 1 \mathrm{H}$, benzene-H), $7.35(\mathrm{~d}, 1 \mathrm{H}$, benzene-H), 7.38 $(\mathrm{d}, 1 \mathrm{H}, J 8.0 \mathrm{~Hz}$, benzene-H), $7.42(\mathrm{~s}, 1 \mathrm{H}$, benzene-H), 7.46 (d, 3H, $J 8.0 \mathrm{~Hz}$, benzene-H); ${ }^{13} \mathrm{C}$ NMR $(100 \mathrm{MHz}$, $\left.\mathrm{CDCl}_{3}\right) \delta 14.5,17.8,20.0,116.3,122.9,125.5,125.6$, $127.8,128.2,128.9,129.1,131.5,131.8,133.4,139.7$, $141.1,141.7,141.9,144.6,156.7 ; \mathrm{IR}(\mathrm{KBr}) v_{\max } / \mathrm{cm}^{-1} 3676$, 2988, 1394, 1265, 1065, 893, 754, 526; low resolution (LR) MS-ESI C ${ }_{29} \mathrm{H}_{21} \mathrm{~F}_{6} \mathrm{SN}$ [M $\mathrm{M}^{+}$calcd.: 529.1; found: 530.1; anal. calcd. for $\mathrm{C}_{29} \mathrm{H}_{21} \mathrm{~F}_{6} \mathrm{SN}$ : C, $65.67 ; \mathrm{H}, 3.89 ; \mathrm{N}, 2.55$; found: C, 65.78; H, 4.00; N, 2.65.

1-(2-Methyl-5-phenyl-3-thienyl)-2-(3,5-dimethyl-6-thiophen2-yl-pyridin-2-yl)perfluorocyclopentene (20)

A stirred anhydrous toluene solution of $6(0.2 \mathrm{~g}$, $0.38 \mathrm{mmol}), 2$-tributylstannylthiophene (1.42 g, $3.8 \mathrm{mmol}$ ) and $\mathrm{Pd}\left(\mathrm{PPh}_{3}\right)_{4}$ was refluxed for $24 \mathrm{~h}$ under argon atmosphere. The reaction was slowly cooled to room temperature, and concentrated in vacuo. After being extracted with ethyl acetate, the organic layer was dried over anhydrous $\mathrm{Na}_{2} \mathrm{SO}_{4}$. The crude product was purified by column chromatography on $\mathrm{Al}_{2} \mathrm{O}_{3}$ using petroleum ether as eluent and afforded $20(0.68 \mathrm{~g}, 34 \%)$ as a colorless crystal. m.p. $157-158{ }^{\circ} \mathrm{C} ;{ }^{1} \mathrm{H}$ NMR $\left(400 \mathrm{MHz}, \mathrm{CDCl}_{3}\right) \delta 1.86$ (s, $\left.3 \mathrm{H},-\mathrm{CH}_{3}\right), 1.94\left(\mathrm{~s}, 3 \mathrm{H},-\mathrm{CH}_{3}\right), 2.48\left(\mathrm{~s}, 3 \mathrm{H},-\mathrm{CH}_{3}\right), 7.05$ $(\mathrm{t}, 1 \mathrm{H}, J 4.0 \mathrm{~Hz}$, thiophene-H), $7.18(\mathrm{~s}, 1 \mathrm{H}$, thiophene- $\mathrm{H})$, $7.21(\mathrm{~d}, 2 \mathrm{H}, J 8.0 \mathrm{~Hz}$, thiophene-H), $7.28(\mathrm{t}, 2 \mathrm{H}, J 8.0 \mathrm{~Hz}$, benzene-H), 7.34 (d, 1H, J 8.0 Hz, pyridine-H), 7.43 (t, $3 \mathrm{H}, J 8.0 \mathrm{~Hz}$, benzene-H); ${ }^{13} \mathrm{C}$ NMR $\left(100 \mathrm{MHz}, \mathrm{CDCl}_{3}\right)$ $\delta 13.5,16.7,20.2,121.5,124.3,124.5,125.9,126.6,126.8$, 126.9, 127.9, 129.1, 129.9, 132.4, 140.8, 140.9, 141.1, 143.3, 143.7, 148.5; IR (KBr) $v_{\max } / \mathrm{cm}^{-1} 3676,2988,1394$, 1250, 1058, 893, 712, 537; LRMS-ESI $\mathrm{C}_{27} \mathrm{H}_{19} \mathrm{~F}_{6} \mathrm{SN}_{2}\left[\mathrm{M}^{+}\right]$ calcd.: 535.1; found: 536.0; anal. calcd. for $\mathrm{C}_{27} \mathrm{H}_{19} \mathrm{~F}_{6} \mathrm{NS}_{2}$ : C, $60.41 ; \mathrm{H}, 3.52 ; \mathrm{N}, 2.51$; found: C, $60.55 ; \mathrm{H}, 3.58 ; \mathrm{N}, 2.62$.
1-(2-Methyl-5-phenyl-3-thienyl)-2-(3,5-dimethyl-6-thiazole2-yl-pyridin-2-yl)perfluorocyclopentene (30)

A stirred anhydrous toluene solution of $6(0.2 \mathrm{~g}$, $0.38 \mathrm{mmol}), 2$-tributylstannylthiazole $(1.58 \mathrm{~g}, 4.3 \mathrm{mmol})$ and $\mathrm{Pd}\left(\mathrm{PPh}_{3}\right)_{4}$ was refluxed for $24 \mathrm{~h}$ under argon atmosphere. The reaction was slowly cooled to room temperature, and concentrated in vacuo. After being extracted with ethyl acetate, the organic layer was dried over anhydrous $\mathrm{Na}_{2} \mathrm{SO}_{4}$. The crude product was purified by column chromatography on $\mathrm{Al}_{2} \mathrm{O}_{3}$ using petroleum ether as eluent and afforded 30 $(0.21 \mathrm{~g}, 34 \%)$ as a colorless crystal. m.p. $150-151{ }^{\circ} \mathrm{C}$; ${ }^{1} \mathrm{H}$ NMR $\left(400 \mathrm{MHz}, \mathrm{CDCl}_{3}\right) \delta 1.89\left(\mathrm{~s}, 3 \mathrm{H},-\mathrm{CH}_{3}\right), 1.92$ (s, $\left.3 \mathrm{H},-\mathrm{CH}_{3}\right), 2.72\left(\mathrm{~s}, 3 \mathrm{H},-\mathrm{CH}_{3}\right), 7.17(\mathrm{~s}, 1 \mathrm{H}$, thiophene-H), 7.21 (d, 1H, J 6.0 Hz, pyridine-H), 7.29 (t, 3H, J 8.0 Hz, benzene-H), $7.33(\mathrm{~d}, 1 \mathrm{H}, J 4.0 \mathrm{~Hz}$, thiazole-H), $7.43(\mathrm{~d}, 2 \mathrm{H}$, $J 8.0 \mathrm{~Hz}$, benzene-H), $7.86(\mathrm{~d}, 1 \mathrm{H}, J 4.0 \mathrm{~Hz}$, thiazole-H); ${ }^{13} \mathrm{C}$ NMR $\left(100 \mathrm{MHz}, \mathrm{CDCl}_{3}\right) \delta 13.4,16.9,19.5,120.5$, $121.3,124.2,124.6,126.9,127.9,131.5,131.7,132.2$, 132.3, 140.9, 141.4, 142.8, 143.2, 146.3, 169.5; IR (KBr) $v_{\max } / \mathrm{cm}^{-1} 2924,1638,1438,1270,1190,1113,992,950$, 851, 753, 539; LRMS-ESI C ${ }_{26} \mathrm{H}_{18} \mathrm{~F}_{6} \mathrm{~S}_{2} \mathrm{~N}_{2}\left[\mathrm{M}^{+}\right]$calcd.: 536.1; found: 537.1; anal. calcd. for $\mathrm{C}_{26} \mathrm{H}_{18} \mathrm{~F}_{6} \mathrm{~S}_{2} \mathrm{~N}_{2}$ : C, 58.07; H, 3.56; N, 5.34; found: C, 58.20; H, 3.38; N, 5.22.

\section{Results and Discussion}

\section{Photochromism}

Figure 3 shows the absorption spectral changes of diarylethene 1 and color changes of diarylethenes 1-3 induced by alternating irradiation with UV light $(297 \mathrm{~nm})$ and visible light $(\lambda>500 \mathrm{~nm})$ in hexane. Upon irradiation at $297 \mathrm{~nm}$ UV light, the colorless solution of diarylethene 10 turned purple quickly and a new absorption band centered at $581 \mathrm{~nm}$ emerged due to the formation of the closed-ring isomer 1c. The colored solution of 1c was bleached entirely upon irradiation with visible light $(\lambda>500 \mathrm{~nm})$ and its absorption spectrum returned to the initial state 1o. Similarly, diarylethenes $\mathbf{2}$ and $\mathbf{3}$ also exhibited favorable photochromism in hexane (Figure S1). Upon irradiation with $297 \mathrm{~nm}$ light, absorption bands in visible region appeared and the colorless solutions of $\mathbf{2 0}$ and 30 turned blue as a result of producing the closed-ring isomers $\mathbf{2 c}$ and $\mathbf{3 c}$, respectively. In photostationary state, the absorption maxima were observed at $618 \mathrm{~nm}$ for $\mathbf{2 c}$ and $623 \mathrm{~nm}$ for $\mathbf{3 c}$. The colored solutions of $\mathbf{2 c}$ and $\mathbf{3 c}$ could be decolorized upon irradiation with visible light $(\lambda>500 \mathrm{~nm})$. When reaching photostationary state, the isosbestic points were observed at $302 \mathrm{~nm}$ for $\mathbf{1 0}, 320 \mathrm{~nm}$ for $\mathbf{2 o}$, and $320 \mathrm{~nm}$ for $\mathbf{3 o}$, indicating that there exists only a two-component photochromic reaction between 


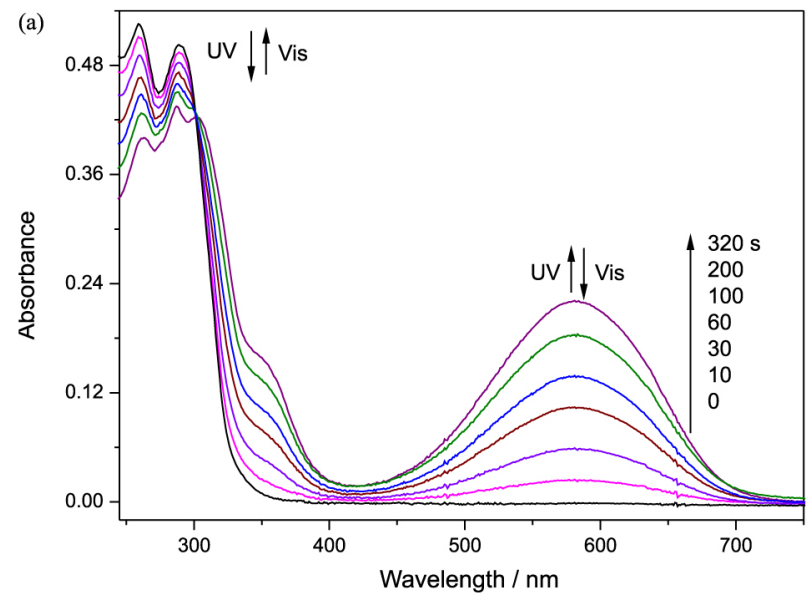

(b)

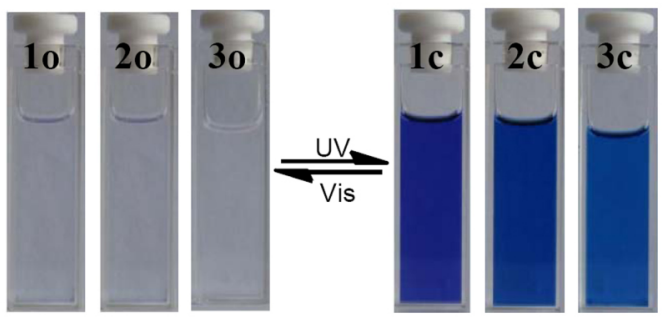

Figure 3. (a) Absorption spectral changes of $\mathbf{1}$ induced by photoirradiation in hexane $\left(2.0 \times 10^{-5} \mathrm{~mol} \mathrm{~L}^{-1}\right)$; and (b) color changes of 1-3.

the open-ring and the closed-ring isomers of these diarylethene derivatives. ${ }^{24,25}$

The photoconversion ratios of $\mathbf{1 - 3}$ from open-ring to closed-ring isomers were determined by HPLC analysis in photostationary state, with values of $73 \%$ for $\mathbf{1 0}, 86 \%$ for 2o, and $87 \%$ for $\mathbf{3 o}$ (Figure 4). In addition, 1-3 have remarkable fatigue resistance and good thermal stability. In hexane, the coloration and decoloration cycles of 1-3 could repeat more than 40 times with the degradation of $9 \%$ for $\mathbf{1 c}, \mathbf{7} \%$ for $\mathbf{2 c}$, and $5 \%$ for $\mathbf{3 c}$ (Figure S2). The thermal stability of $\mathbf{1 0 - 3 o}$ and $\mathbf{1 c - 3 c}$ was checked in hexane at room temperature and at $341 \mathrm{~K}$. The results showed that no decomposition was detected by UV-Vis spectroscopy for all of the hexane solutions. The thermal decay profiles of $\mathbf{1 c}$ at various temperatures are shown in Figure 5. The results indicated that the absorbance decay of $\mathbf{1 c}$ at the absorption maxima obeyed the first-order thermal cycloreversion kinetics. The thermal fading changes of $\mathbf{2 c}$ and $\mathbf{3 c}$ were also measured in the range of 298-343 K (Figure S3). According

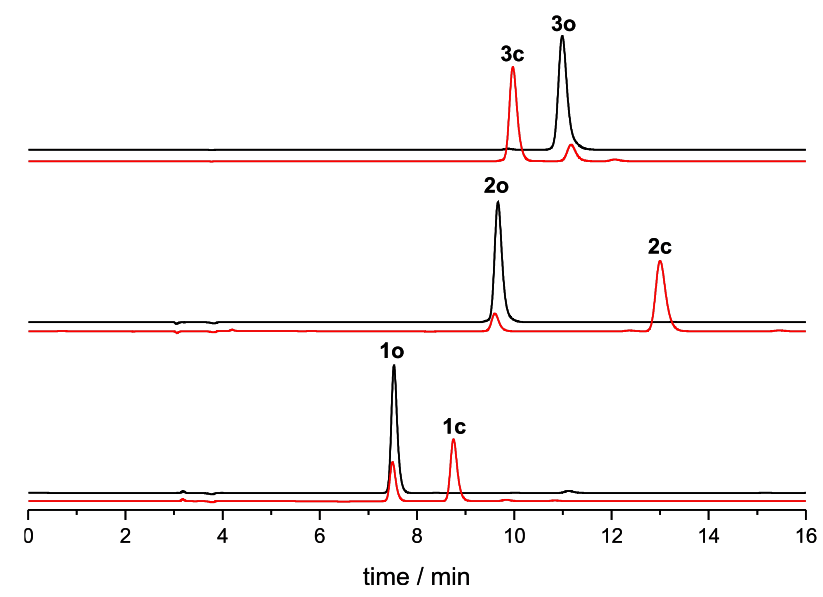

Figure 4. Photoconversion ratios of 1-3 in the photostationary state by HPLC analysis. Eluent: hexane/tetrahydrofuran $98: 2 \mathrm{v} / \mathrm{v}$ for 1-3; flow rate $=1.0 \mathrm{~mL} \mathrm{~min}^{-1}$.

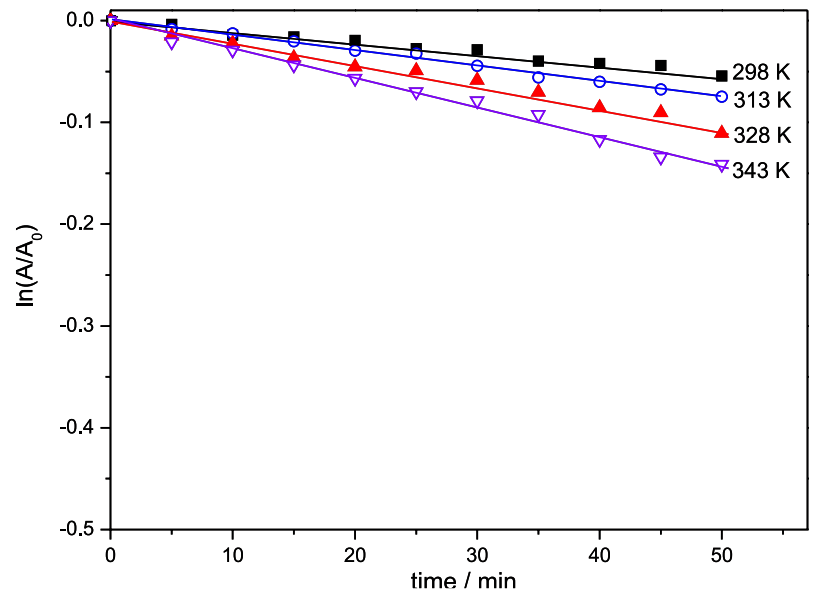

Figure 5. Thermal fading of $\mathbf{1 c}$ in hexane at various temperatures.

to the Arrhenius equation, the activation energies were determined as $18.7 \mathrm{~kJ} \mathrm{~mol}^{-1}$ for $\mathbf{1 c}, 38.4 \mathrm{~kJ} \mathrm{~mol}^{-1}$ for $\mathbf{2 c}$, and $36.2 \mathrm{~kJ} \mathrm{~mol}^{-1}$ for $3 \mathrm{c}$. The half-lifetimes at $298 \mathrm{~K}$ were $56 \mathrm{~h}$ for $\mathbf{1 c}, 126 \mathrm{~h}$ for $\mathbf{2 c}$, and $67 \mathrm{~h}$ for $\mathbf{3 c}$, respectively. Moreover, the thermal cycloreversion rates of $\mathbf{1 c - 3 \mathbf { c }}$ were distinctly different at $298 \mathrm{~K}$, and the values gradually increased in going from thienyl to thiazyl to phenyl groups. For each compound, its thermal cycloreversion rate accelerated with the increment of temperature.

The photochromic parameters of diarylethenes 1-3 in hexane are summarized in Table 1. It was clearly found that the different peripheral heteroaryl substituents had a significant effect on the photochromic properties of these diarylethenes, including the absorption maxima, molar absorption coefficients, quantum yields of cyclization and cycloreversion, and photoconversion ratios. For the three derivatives, the absorption maxima of both their open-ring and closed-ring isomers increased in the order of phenyl $<$ thienyl < thiazyl substituent, and their molar absorption coefficients increased in the order of phenyl $<$ thiazyl $<$ thienyl substituent. The quantum yields of cyclization and 
Table 1. Photochromic parameters of $\mathbf{1 - 3}$ in hexane $\left(2.0 \times 10^{-5} \mathrm{~mol} \mathrm{~L}^{-1}\right)$ at room temperature

\begin{tabular}{lccccc}
\hline Compound & $\begin{array}{c}\lambda_{\mathrm{o}, \max } / \mathrm{nm}^{\mathrm{a}} \\
\left(\varepsilon /\left(\mathrm{L} \mathrm{mol}^{-1} \mathrm{~cm}^{-1}\right)\right)\end{array}$ & $\begin{array}{c}\lambda_{\mathrm{c}, \max } / \mathrm{nm}^{\mathrm{b}} \\
\left(\varepsilon /\left(\mathrm{L} \mathrm{mol}^{-1} \mathrm{~cm}^{-1}\right)\right)\end{array}$ & $\Phi_{0-\mathrm{c}}$ & $\Phi^{\mathrm{c}}$ & $\Phi_{\mathrm{c}-0}$ \\
\hline $\mathbf{1}$ & $259\left(2.6 \times 10^{4}\right)$ & $581\left(1.1 \times 10^{4}\right)$ & 0.32 & 0.03 & 73 \\
$\mathbf{3}$ & $263\left(3.3 \times 10^{4}\right)$ & $618\left(1.8 \times 10^{4}\right)$ & 0.60 & 0.01 & 86 \\
\hline
\end{tabular}

${ }^{a}$ Absorption maxima of open-ring isomers; babsorption maxima of closed-ring isomers; ${ }^{c}$ quantum yields of open-ring $\left(\Phi_{\mathrm{o-c}}\right)$ and closed-ring isomers $\left(\Phi_{\mathrm{c}-\mathrm{o}}\right)$, respectively; ${ }^{\mathrm{d}}$ photoconversion ratios $(\mathrm{PR} \%)$ of $\mathbf{1 - 3}$ in the photostationary state. $\varepsilon$ : molar absorption coefficient.

cycloreversion were measured using 1,2-bis(2-methyl-5phenyl-3-thienyl)perfluorocyclopentene as a reference. ${ }^{26}$ As shown in Table 1, the cyclization quantum yields of diarylethenes with a five-membered peripheral heteroaryl group (such as in compounds $\mathbf{2}$ and $\mathbf{3}$ ) notably enhanced, and their cycloreversion quantum yields decreased slightly, as compared to diarylethene with a six-membered peripheral heteroaryl group (such as in compound 1). In photostationary state, the photoconversion ratios of $\mathbf{2}$ and $\mathbf{3}$ were also much higher than that of $\mathbf{1}$. The results revealed that using five-membered heteroaryl rings (such as compounds $\mathbf{2}$ and $\mathbf{3}$ ) as peripheral substituents could effectively enhance the cyclization quantum yields and photoconversion ratios of these diarylethene derivatives.

\section{Crystal structures and photochromism in the crystalline phase}

Single crystals of $\mathbf{1 0 - 3 0}$ were obtained via slow evaporation of their individual hexane solution, and the final structural conformations were provided by X-ray crystallographic diffraction analysis. The Oak Ridge thermal ellipsoid plot (ORTEP) drawings and photochromic processes in the crystalline phase are shown in Figure 6; the crystal data are summarized in Supplementary Information. 10-3o were packed in anti-parallel conformations in their individual crystalline phases. The corresponding dihedral angles and the distances between the reactive carbon atoms of 1o-3o are summarized in Table 2. The dihedral angle between pyridine and adjacent benzene was $64.1^{\circ}$ for 10 , the dihedral angle between pyridine and adjacent thiophene was $17.7^{\circ}$ for 20 and that between pyridine and adjacent thiazole was $5.6^{\circ}$ for $\mathbf{3 o}$, revealing that the coplanarity notably enhanced by the order of $10<20<30$. Consequently, the $\pi$-conjugation extension of the aromatic systems gradually increased in going from $\mathbf{1 0}<\mathbf{2 0}<\mathbf{3 0}$, resulting in an evident increment in their absorption maxima. The distances between the two reactive carbons were $3.688 \AA$ for $\mathbf{1 0}, 3.563 \AA$ for $\mathbf{2 0}$, and $3.651 \AA$ for $\mathbf{3 o}$, which were short enough for the occurring of photocyclization reaction in the hexatriene unit. ${ }^{27,28}$ As expected, the three crystals exhibited reversible photoisomerization reactions by photoirradiation in the crystalline phases. Upon irradiation with UV light, the colorless crystals of 10-3o turned into the colored crystals 1c-3c. Reversely, the colored crystals could be bleached into the corresponding colorless ones upon irradiation with appropriate visible light. In addition, the X-ray structural analysis indicates that weak intramolecular interactions exist in their individual crystalline phases. The distances between $\mathrm{N} 1$ and adjacent $\mathrm{F}$ atoms were estimated to be $2.994 \AA$ for $\mathbf{1 0}, 2.857 \AA$ for $\mathbf{2 0}$, and $2.889 \AA$ for $\mathbf{3 0}$, which are less than the sum of the van der Waals radii of the $\mathrm{N}$ $(1.55 \AA)$ and $\mathrm{F}(1.47 \AA)$ atoms. ${ }^{29}$ The interatomic distances between N1 and S2 atoms were estimated to be $2.812 \AA$ for 20 and $2.796 \AA$ for 3o, which are also less than the sum of the van der Waals radii of the $\mathrm{N}(1.55 \AA)$ and $\mathrm{S}$ $(1.80 \AA)$ atoms. The results revealed that the $\mathrm{N} \cdots \mathrm{F}$ and $\mathrm{N}$... S heteroatom-contact interactions existed in $\mathbf{2 0}$ and 3o, which could be useful for stabilizing their photoreactive formations in both crystalline and solution phases. ${ }^{29}$ The experimental evidence also elucidated that the higher cyclization quantum yields of $\mathbf{2}$ and $\mathbf{3}$, compared to that of 1 (no $\mathrm{N}$...S contact), were a result of the synergistic effect of both $\mathrm{N} \cdots \mathrm{F}$ (conformational aspect) and $\mathrm{N} \cdots \mathrm{S}$ (energetic aspect) interactions. ${ }^{20,29}$

\section{Fluorescence}

As observed for most of the reported diarylethenes, ${ }^{30-32}$ diarylethenes 1-3 exhibited notable fluorescent switches by photoirradiation. The fluorescence changes of diarylethene $\mathbf{1}$ in hexane $\left(5.0 \times 10^{-5} \mathrm{~mol} \mathrm{~L}^{-1}\right)$ are shown in Figure 7. When excited at $300 \mathrm{~nm}$, the emission peak of 10 was observed at $446 \mathrm{~nm}$. Upon irradiation with $297 \mathrm{~nm}$ light, the emission intensity of $\mathbf{1 0}$ decreased notably due to the formation of the closed-ring isomer $\mathbf{1 c}$. Reversely, the back irradiation with appropriate visible 

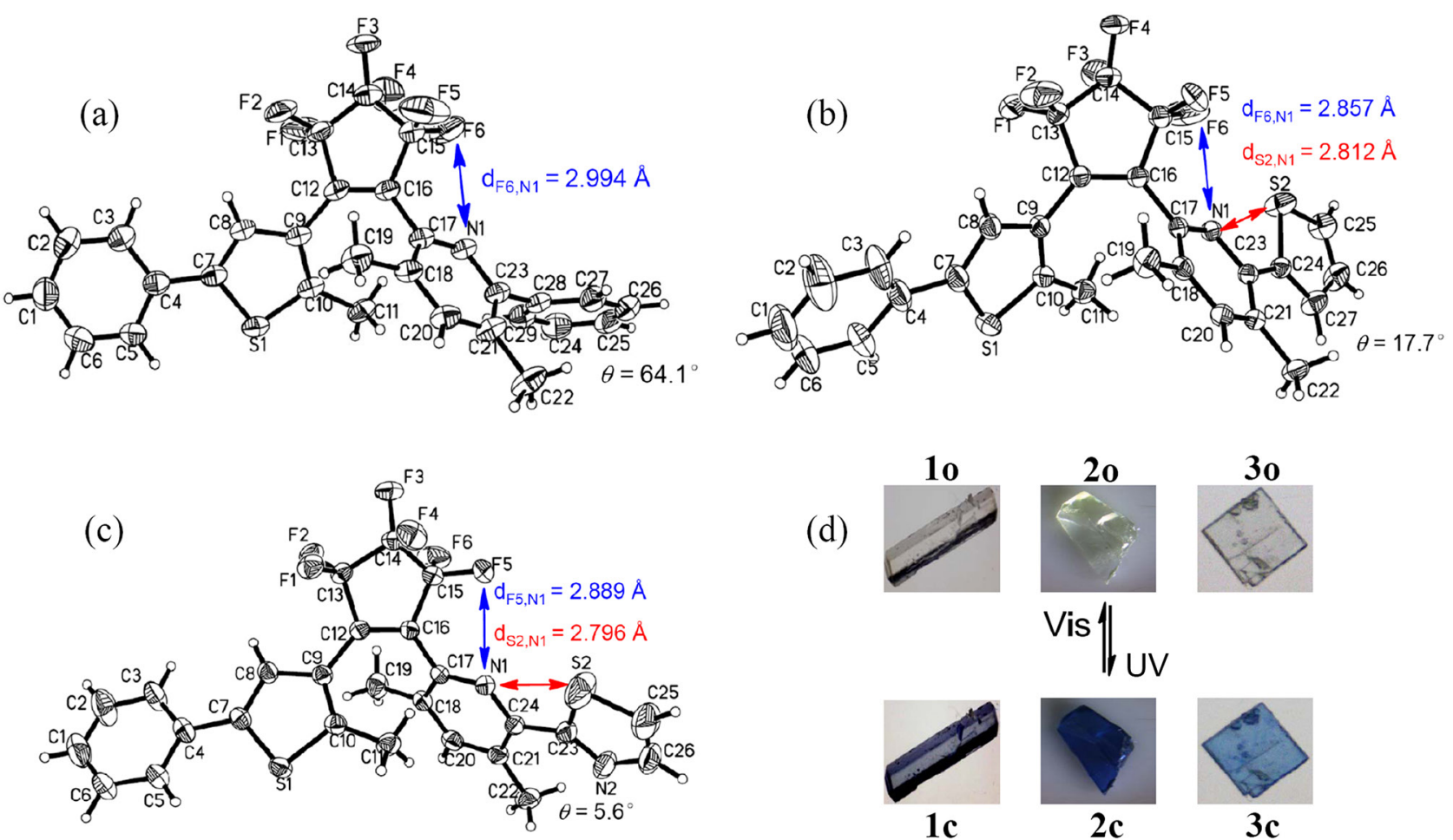

(d)
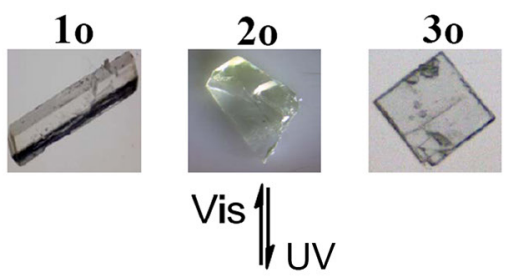

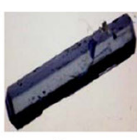

1c

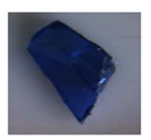

2c

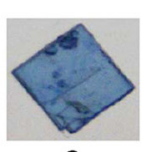

3c

Figure 6. ORTEP drawings of crystals of 1o-3o and photos demonstrating their photochromism in the single crystalline phase: (a) 1o; (b) 20; (c) 3o; and (d) photos demonstrating the photochromism of $\mathbf{1 0 - 3 0}$ in the crystalline phase.

Table 2. Distances between the reacting carbon atoms and dihedral angles of 1o-3o

\begin{tabular}{|c|c|c|c|c|c|c|}
\hline \multirow{2}{*}{ Compound } & \multirow{2}{*}{\multicolumn{2}{|c|}{$\mathrm{d} / \AA$}} & \multicolumn{4}{|c|}{$\theta^{\mathrm{a}} /$ degree } \\
\hline & & & $\theta_{1}$ & $\theta_{2}$ & $\theta_{3}$ & $\theta_{4}$ \\
\hline 10 & $\mathrm{C} 10 \cdots \mathrm{C} 18$ & 3.688 & 10.1 & 39.7 & 62.1 & 64.1 \\
\hline 20 & $\mathrm{C} 10 \cdots \mathrm{C} 18$ & 3.563 & 20.2 & 42.6 & 50.0 & 17.7 \\
\hline 30 & $\mathrm{C} 10 \cdots \mathrm{C} 18$ & 3.651 & 11.5 & 47.6 & 56.7 & 5.6 \\
\hline
\end{tabular}

${ }^{\mathrm{a}} \theta_{1}$ : dihedral angle between benzene and thiophene; $\theta_{2}$ : dihedral angle between thiophene and cyclopentene; $\theta_{3}$ : dihedral angle between cyclopentene and pyridine; $\theta_{4}$ : dihedral angle between pyridine and adjacent benzene, thiophene, thiazole, respectively. d: Distance between the reacting carbon atoms.

light regenerated the open-ring isomer 10 and recovered the original emission intensity. When photostationary state was reached, the fluorescent modulation efficiency was $67 \%$ for $\mathbf{1}$. Just like 1, 2 and $\mathbf{3}$ also showed remarkable fluorescent switches in hexane upon alternating irradiation with UV and visible light (Figure S4); when excited at $300 \mathrm{~nm}$, the emission peaks of $\mathbf{2 0}$ and $\mathbf{3 0}$ were observed at 439 , and $444 \mathrm{~nm}$, respectively. In the photostationary state, the fluorescent modulation efficiencies were $69 \%$ for $\mathbf{2}$, and $\mathbf{7 3 \%}$ for $\mathbf{3}$. The residual fluorescence of $\mathbf{1 - 3}$ in photostationary state may be attributed to the incomplete cyclization reaction and the existence of parallel conformation..$^{13}$ The results indicated that the heteroaryl unit linked to the pyridine moiety had no obvious effect on the fluorescence behavior of these diarylethene derivatives.

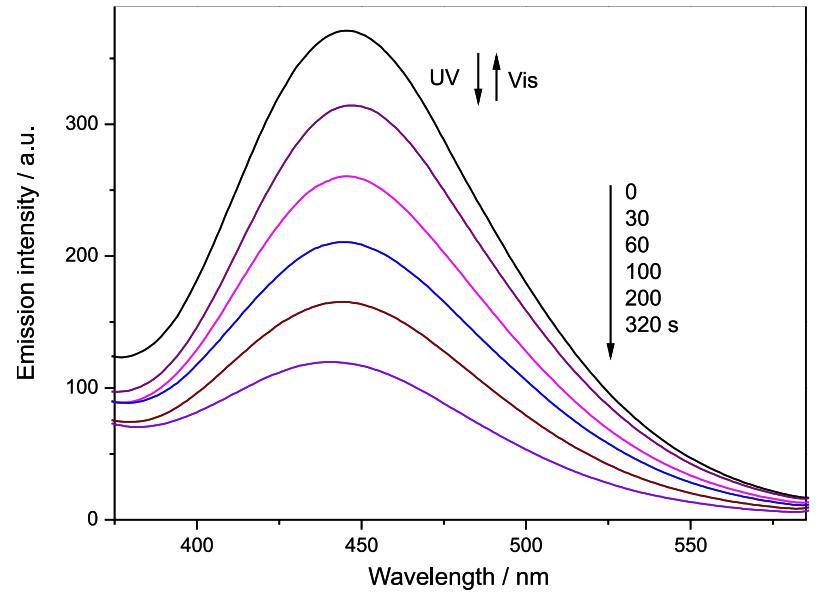

Figure 7. Fluorescence spectral changes of 1 in hexane $\left(5.0 \times 10^{-5} \mathrm{~mol} \mathrm{~L}^{-1}\right)$, excited at $300 \mathrm{~nm}$. 
Compared to the pyridine-containing diarylethenes with the similar molecular skeleton, ${ }^{15}$ the fluorescent modulation efficiency of the three diarylethenes with a peripheral heteroaryl group enhanced notably during the process of photoisomerization, indicating that the diarylethenes are ideal for practical applications in certain fluorescent switching devices. ${ }^{4,33,34}$

\section{Conclusions}

In summary, three new pyridine-containing diarylethenes with a variable peripheral heteroaryl unit have been synthesized to elucidate the effects of the peripheral heteroaryl substituents on the photochromic properties. These compounds exhibited notable photochromism and acted as an evident fluorescence switch in solution. Our experimental results showed that the cyclization quantum yields were enhanced by introducing thienyl and thiazyl to the 6-position of the pyridine moiety, which was ascribed to the $\mathrm{N}$...S heteroatom-contact interactions. The results will provide a useful strategy for the design of new diarylethenes with tunable photochromic behaviors.

\section{Supplementary Information}

Supplementary data are available free of charge at http://jbcs.sbq.org.br as PDF file. Further details on the crystal structures have been deposited in the Cambridge Crystallographic Data Centre as supplemental publications CCDC 1014299 for 1o, CCDC 1014298 for 2o, CCDC 1014297 for 3o. Copies of the data can be obtained, free of charge, on application to CCDC, 12 Union Road, Cambridge CB2 1EZ, UK (fax: +44 01223336033 or email: deposit@ccdc.cam.ac.uk).

\section{Acknowledgments}

This work was supported by the National Natural Science Foundation of China (21262015, 51373072), the Project of Jiangxi Advantage Sci-Tech Innovative Team (20142BCB24012), the Science Funds of Natural Science Foundation of Jiangxi Province (20132BAB203005), the Project of the Science Funds of Jiangxi Education Office (KJLD12035, GJJ12587, GJJ13577), and the Masters' Innovative Foundation of Jiangxi Province (YC2014-S432, YC2014-S433).

\section{References}

1. Irie, M.; Chem. Rev. 2000, 100, 1685.

2. Kawata, S.; Kawata, Y.; Chem. Rev. 2000, 100, 1777.
3. Tian, H.; Yang, S. J.; Chem. Soc. Rev. 2004, 33, 85.

4. Irie, M.; Fukaminato, T.; Matsuda, K.; Kobatake, S.; Chem. Rev. 2014, 114, 12174.

5. Li, W. L.; Jiao, C. H.; Li, X.; Xie, Y. S.; Nakatani, K.; Tian, H.; Zhu, W. H.; Angew. Chem., Int. Ed. 2014, 53, 4603.

6. Ichikawa, T.; Morimoto, M.; Sotome, H.; Ito, S.; Miyasaka, H.; Irie, M.; Dyes Pigm. 2016, 126, 186.

7. Uno, K.; Niikura, H.; Morimoto, M.; Ishibashi, Y.; Miyasaka, H.; Irie, M.; J. Am. Chem. Soc. 2011, 133, 13558.

8. Higashiguchi, K.; Matsuda, K.; Asano, Y.; Murakami, A.; Nakamura, S.; Irie, M.; Eur. J. Org. Chem. 2005, 91.

9. Uchida, K.; Matsuoka, T.; Sayo, K.; Iwamoto, M.; Hayashi, S.; Irie, M.; Chem. Lett. 1999, 835.

10. Takeshita, M.; Ogawa, O.; Miyata, K.; Yamato, T.; J. Phys. Org. Chem. 2003, 16, 148.

11. Uchida. K.; Nakamura, S.; Irie, M.; Res. Chem. Intermed. 1995, 21,861 .

12. Liu, G.; Pu, S. Z.; Wang, R. J.; Org. Lett. 2013, 15, 980.

13. Pu, S. Z.; Fan, C. B.; Miao, W. J.; Liu, G.; Tetrahedron 2008, 64, 9464.

14. Yumoto, K.; Irie, M.; Matsuda, K.; Org. Lett. 2008, 10, 2051.

15. Pu, S. Z.; Yan, P. J.; Liu, G.; Miao, W. J.; Liu, W. J.; Tetrahedron Lett. 2011, 52, 143.

16. Liu, G.; Liu, M.; Pu, S. Z.; Fan, C. B.; Cui, S. Q.; Dyes Pigm. 2012, 95, 553.

17. Garciak, Y.; Ksenofontov, V.; Lapouyade, R.; Naik, A. D.; Robert, F.; Gütlich, P.; Opt. Mater. 2011, 33, 942.

18. Spangenberg, A.; Métivier, R.; Gonzalez, J.; Nakatani, K.; Yu, P.; Giraud, M.; Léaustic, A.; Guillot, R.; Uwada, T.; Asahi, T.; Adv. Mater. 2009, 21, 309.

19. Al-Atar, U.; Fernandes, R.; Johnsen, B.; Baillie, D.; Branda, N. R.; J. Am. Chem. Soc. 2009, 131, 15966.

20. Pu, S. Z.; Zheng, C. H.; Sun, Q.; Liu, G.; Fan, C. B.; Chem. Commun. 2013, 49, 8036.

21. Levchenko, K. S.; Barachevski, V. A.; Kobeleva, O. I.; Venidiktova, O. V.; Valova, T. M.; Bogacheva, A. M.; Chudov, K. A.; Grebennikov, E. P.; Shmelin, P. S.; Poroshin, N. O.; Adamov, G. E.; Yarovenko, V. N.; Krayushkin, M. M.; Tetrahedron Lett. 2015, 56, 1085.

22. Luo, Q. F.; Liu, M. Q.; Cheng, R. J.; Liu, Y.; Dyes Pigm. 2015, 113,602 .

23. Migulin, V. A.; Krayushkin, M. M.; Barachevsky, V. A.; Kobeleva, O. I.; Novikov, V. V.; Lyssenko, K. A.; Tetrahedron 2015, 71, 584 .

24. Kawai, S.; Nakashima, T.; Atsumi, K.; Sakai, T.; Harigai, M.; Imamoto, Y.; Kamikubo, H.; Kataoka, M.; Kawai, T.; Chem. Mater. 2007, 19, 3479.

25. Sun, Z. Y.; Li, H.; Liu, G.; Fan, C. B.; Pu, S. Z.; Dyes Pigm. 2014, 106, 94.

26. Irie, M.; Lifka, T.; Kobatake, S.; Kato, N.; J. Am. Chem. Soc. 2000, 122, 4871 . 
27. Shibata, K.; Muto, K.; Kobatake, S.; Irie, M.; J. Phys. Chem. A 2002, 106, 209.

28. Morimoto, M.; Irie, M.; Chem. Commun. 2005, 3895.

29. Bondi, A.; J. Phys. Chem. 1964, 68, 441.

30. Tian, H.; Chen, B. Z.; Tu, H. Y.; Müllen, K.; Adv. Mater. 2002, $14,918$.

31. Feng, Y. L.; Yan, Y. L.; Wang, S.; Zhu, W. H.; Qian, S. X.; Tian, H.; J. Mater. Chem. 2006, 16, 3685.
32. Zou, Y.; Yi, T.; Xiao, S. Z.; Li, F. Y.; Li, C. Y.; Gao, X.; Wu, J. C.; Yu, M. X.; Huang, C. H.; J. Am. Chem. Soc. 2008, 130, 15750.

33. Yun, C.; You, J.; Kim, J.; Huh, J.; Kim, E.; J. Photochem. Photobiol., C 2009, 10, 111.

34. Zhang, J. J.; Zou, Q.; Tian, H.; Adv. Mater. 2013, 25, 378

Submitted: January 8, 2016 Published online: March 22, 2016 